\title{
A ADEQUABILIDADE DAS FONTES DE PESQUISA JURÍDICA PARA PRODUÇÃO DO CONHECIMENTO JURÍDICO CIENTÍFICO INOVADOR
}

\author{
Mônica Mota Tassigny ${ }^{1}$ \\ Andréa de Boni Nottingham ${ }^{2}$
}

\section{Resumo}

O escopo do presente artigo é debater a adequabilidade das fontes de pesquisa jurídica para produção do conhecimento científico, bem como realçar sua pertinência enquanto fontes do Direito, diversas da especificidade da lógica da metodologia jurídica. O problema parte da crítica contemporânea acerca dos trabalhos jurídicos, no que diz respeito ao uso da pesquisa eminentemente bibliográfica, baseada primordialmente em livros monográficos, mostrando-se, desse modo, relevante a discussão sobre a plausibilidade de fontes da pesquisa jurídica. Assim, busca-se responder se o modo de utilização das fontes de pesquisa pode influenciar, diretamente, na qualidade do trabalho jurídico e, consequentemente, na produção do conhecimento científico e não apenas em lógica do discurso jurídico. Objetiva-se avaliar a adequabilidade das fontes da pesquisa jurídica e se essas têm sido responsáveis pela produção de um conhecimento jurídico científico inovador. Trata-se de ensaio teórico e documental, de abordagem qualitativa. Quanto aos objetivos, é do tipo descritiva e exploratória, vez que busca descrever e interpretar o problema observado. Quanto à utilização dos resultados é do tipo pura, cujo intuito é a ampliação do conhecimento acerca do tema. Como resultado, infere-se que é necessário ao pesquisador jurídico científico utilizar de diversos tipos de fontes de pesquisa, sem limitar-se exclusivamente a fonte bibliográfica, desde que de forma compatível ao objeto de pesquisa e às próprias fontes do Direito, para que possa inovar na produção do saber jurídico de melhor qualidade, que de fato apresentem soluções teórico-práticas e viáveis aos problemas da área em foco.

\footnotetext{
${ }^{1}$ Doutorado em Sócio-Economie du développement - Ecole des Hautes Études en Sciences Sociales (2002) e Doutorado em Educação pela Universidade Federal do Ceará (2002). Membro titular da Academia Metropolitana de Letras de Fortaleza. Professora Dra. Titular do Programa de Pós-Graduação (Mestrado e Doutorado) em Direito Constitucional pela Universidade de Fortaleza - UNIFOR. E-mail: monica.tass@gmail.com
} 
Palavras-chave: Fontes de pesquisa jurídica; Conhecimento científico; Fontes do Direito.

\section{INTRODUÇÃO}

A discussão acerca da qualidade dos trabalhos jurídicos científicos desenvolvidos nas universidades tem sido cada vez mais frequente na comunidade acadêmica. A busca por mudanças na forma de produzir ciência na área do Direito vem determinando os desafios de formação de um novo panorama na pesquisa jurídica. A exigência por textos originais e atuais faz com que o pesquisador tenha que inovar no modo de fazer pesquisa.

Com efeito, alguns erros e equívocos são apontados por estudiosos da temática em relação à produção de trabalhos jurídicos, desde problemas substanciais até problemas formais. Nitish Monebhurrun (informação verbal) $)^{3}$, por exemplo, nas suas aulas e palestras sobre a produção jurídico-científica, costuma indicar como problemas estruturais a comum utilização de um capítulo, ou seção, inteiramente voltado à explanação da parte histórica, muitas vezes, sem qualquer conexão lógica com o restante do texto; e a descrição excessiva de institutos jurídicos sem que o autor mostre o seu entendimento, o seu raciocínio sobre o que está discutindo.

Quanto aos problemas substanciais, o autor supracitado destaca a falta de dedicação do pesquisador à reflexão sobre o tema estudado. Aponta que o correto seria primeiro refletir exaustivamente sobre o tema, lançar hipóteses e só então começar a escrever, após ter a ideia bem formada. A distância crítica é outro defeito identificado, pois o pesquisador se exime de apresentar sua opinião crítica e tende apenas a indicar o posicionamento da doutrina, sem construir argumentos de defesa ou refutação de tal posicionamento.

Há ainda que se falar do descuido ao se realizar trabalhos multidisciplinares. Nitish Monebhurrun (informação verbal) ${ }^{4}$ alega que, muitas vezes, o pesquisador do Direito acha-se capaz de opinar sobre todos os demais campos das ciências humanas e sociais e o faz de forma superficial. Isso não quer dizer que o trabalho jurídico não possa ser multidisciplinar, mas se assim for, deve ser produzido em forma de diálogo com as outras ciências, de modo a contemplar trocas com profissionais habilitados em cada ramo.

Diante disso, infere-se, para além das evidências expostas, que a origem dos defeitos supracitados pode estar na forma errada de investigação relacionada às fontes da pesquisa. Assim, deduz-se que, antes mesmo de

\footnotetext{
${ }^{2}$ Mestre em Direito Constitucional pelo Programa de Pós-Graduação em Direito Constitucional da Universidade de Fortaleza (PPGD-UNIFOR).E-mail: andreadeboni@edu.unifor.br

${ }^{3}$ Palestra proferida pelo Prof. Nitish Monebhurrun no XIII Congresso Brasileiro de Direito Internacional - comércio, globalização e formação do capital social, realizado na Universidade de Fortaleza - UNIFOR, em Fortaleza, em agosto de 2015.
} 
iniciar uma atividade de investigação acerca do problema determinado, o pesquisador deve conhecer bem as fontes e os materiais para escolher a maneira mais adequada de investigar determinado fenômeno.

Nesse ponto, reside um dos maiores problemas dos autores da área jurídica: o vício pelo desenvolvimento de trabalhos eminentemente bibliográficos, limitados a compilar teses doutrinárias preexistentes e repetir o que já está posto, sem variar sequer a forma de exposição.

Desse modo, parte-se da hipótese que as ocorrências acima relatadas pelo Prof. Nitish Monebhurrun (2015) têm a ver com a escolha equivocada das fontes de pesquisa, que leva a problemas na construção das argumentações jurídicas e científicas, que se limitam apenas a descrever determinados fenômenos a partir da repetição de doutrinas.

Dessa forma, busca-se com este artigo, responder a seguinte indagação: As fontes comumente utilizadas na pesquisa jurídica são adequadas? Essa escolha pode, de fato, influenciar na qualidade do trabalho jurídico e, consequentemente, na produção do conhecimento jurídico científico inovador?

Isto posto, o objetivo geral perfaz-se em avaliar se a utilização adequada das fontes (bem como, a utilização das fontes adequadas) de pesquisa jurídica é responsável pela produção de um conhecimento jurídico científico original e inovador. Os objetivos específicos, por sua vez, consistem em identificar as opções diversas de fontes de pesquisa jurídica na área do Direito e debater a necessidade de comunicação e compatibilidade entre os tipos de fontes de pesquisa jurídica e as fontes científicas do Direito.

A metodologia utilizada no desenvolvimento deste artigo é bibliográfica, baseada em livros clássicos de metodologia científica e em artigos de periódicos, bem como documental, vez que se utiliza de fonte (primária) que não sofreu qualquer trato científico, como por exemplo, informações verbais captadas do seminário ministrado durante XIII Congresso Brasileiro de Direito Internacional, realizado na Universidade de Fortaleza em 2015.

Ainda sobre os aspectos metodológicos, a pesquisa bibliográfica e documental, quanto à abordagem, qualitativa, vez que parte de uma reflexão sobre as ações humanas e sociais; do tipo descritiva e exploratória, quanto aos objetivos, pois busca descrever, explicar e interpretar o problema observado; e do tipo pura quanto a utilização dos resultados, vez que tem como intuito a ampliação do conhecimento acerca do tema e tudo que lhe envolve.

O desenvolvimento deste artigo divide-se em três tópicos em que o primeiro deles aborda o tema conhecimento, método e fontes científicas, fundamentando conceitos necessários ao entendimento do bom desenvolvimento da pesquisa na área do Direito. O segundo tópico aborda a pesquisa jurídica, a ciência e a

\footnotetext{
${ }^{4}$ Palestra proferida por Nitish Monebhurrun no XIII Congresso Brasileiro de Direito Internacional - comércio, globalização e formação do capital social, realizado na Universidade de Fortaleza - UNIFOR, em Fortaleza, em agosto de 2015.
} 
argumentação. Por fim, o terceiro tópico tratará especificamente de como essa adequação da utilização das fontes é necessária para que o pesquisador possa estar apto à produção de conhecimento e não somente à reprodução, mas a possibilidade de inovar.

\section{CONHECIMENTO, MÉTODO E FONTES DE PESQUISA}

Há muitos anos se discute a origem do conhecimento humano, nesse aspecto, surgiram teorias com diferentes bases, como por exemplo, o empirismo e o racionalismo clássico, o primeiro atribui a fonte do conhecimento à observação, e o segundo à razão; o primeiro teve como maior defensor Bacon, e o segundo Descartes. No entanto, nenhuma das duas foi capaz de demonstrar a existência de uma verdade absoluta. Diante dessa constatação, Popper (1982, p. 32) afirma que nem razão, nem observação, podem ser definidas como fontes últimas do conhecimento.

Dessa forma, não há, portanto, uma única fonte de conhecimento, mas várias que se complementam, sempre no intuito de se chegar o mais próximo da verdade, que nunca será absoluta, mas sempre aproximativa. Popper (1982, p. 56) entende, ainda, que a tradição é uma das principais fontes de conhecimento, pois é consequência da nossa experiência de vida, o que ouvimos, vemos, sentimos ao longo dos anos, sempre que se busca um novo conhecimento significa que já temos formado em nossas mentes pré-compreensões, produtos da tradição.

Nesse contexto, pesquisar é, no sentido mais amplo, o ato de buscar conhecimento e essa procura nasce de uma indagação, de um questionamento da vontade de descobrir algo que ainda não se sabe ou, de se comprovar algo que se acredita que se sabe. Pode se realizar por meio da observação de um objeto, da experimentação prática de algo, da leitura de um texto ou de uma conversa, por exemplo (ALMEIDA JUNIOR, 1988, p. 109), ou seja, nunca se parte de uma consciência vazia e o resultado alcançado nunca é absoluto, indiscutível e incontestável, mas sempre passível de crítica, de refutação. Assim posto, não se pode afirmar que exista apenas um tipo de fonte ou muito menos que existe uma hierarquia entre fontes.

A pesquisa científica busca se aproximar da verdade, verdade no sentido de realidade, ou de verossimilhança com a realidade, e, para tanto, utiliza-se de métodos que lhe dê um direcionamento, permita-lhe ocorrer ordenadamente, garantindo-lhe maior segurança quanto aos resultados alcançados. O critério de cientificidade da pesquisa, portanto, está no método por ela adotado.

Vale ressaltar que o método não é exclusivo da ciência, pode-se obedecer a um método de forma intuitiva, sem que se esteja no campo da ciência, porém, a recíproca não é verdadeira, para que se tenha ciência é fundamental a utilização de um método (LAKATOS; MARCONI, 2003, p. 83): 
A ciência pode ser caracterizada como uma forma de conhecimento objetivo, racional, sistemático, geral, verificável e falível. O conhecimento científico é objetivo porque descreve a realidade independentemente dos caprichos do pesquisador. E racional porque se vale sobretudo da razão, e não de sensação ou impressões, para chegar a seus resultados. É sistemático porque se preocupa em construir sistemas de idéias organizadas racionalmente e em incluir os conhecimentos parciais em totalidades cada vez mais amplas (...) (GIL, 2008, p.8).

Assim, a pesquisa científica, em obediência ao método, gera conhecimento de natureza também científica. De acordo com Eduardo Bittar (2015, p. 35), “a ciência é, em verdade, o conhecimento sistematizado, testado, organizado, diluído em uma trama de postulados metodológicos”. Diferencia-se, portanto, do senso comum, da opinião que pertence a qualquer pessoa e que pode ser emitida sem qualquer vínculo metodológico que leve a uma comprovação das ideias (MATALLO JUNIOR, 1988, p. 15).

A pesquisa científica caracteriza-se por uma investigação sistemática (MEZZAROBA; MONTEIRO, 2004, p. 105) sobre um determinado objeto, que deverá ser obrigatoriamente definido e delimitado; isto é: problematizado a partir de uma que move o pesquisador e o leva a empreender uma jornada de investigação.

Já o senso comum, esse conjunto de informações que se obtém sem saber ao certo de onde, como ou porque, e sem que se possa justificar, pode ser conectado àquilo que Popper (1982, p. 56) chamou de tradição e pode ser o ponto de partida para descoberta de algo novo, que desconstrua entendimentos anteriores, ou confirme-os, mas que, de qualquer forma, para poder ser chamado de ciência, esse processo de construção e desconstrução de teses deve obedecer a métodos e, por isso, ser capaz de ser evidenciado e comprovado.

A metodologia, por sua vez, é a ciência que se destina ao estudo dos métodos, ou seja, das técnicas, fontes, instrumentos, regras e procedimentos que devem ser seguidas para a produção de um trabalho científico de qualidade, é o estudo do caminho a ser percorrido na produção da ciência, por meio de uma pesquisa, que, no caso em foco, liga-se ao campo do Direito.

Por sua vez existem métodos, na pesquisa jurídica, não necessariamente científicos que são os critérios que permitem construir, erguer e concatenar uma argumentação jurídica lógica (MONEBHURRUN, 2015 , p. 35), que investigue um problema, proponha uma hipótese e comprove adequabilidade dessa solução por intermédio da argumentação (informação verbal) ${ }^{5}$. O resultado que se espera da pesquisa nessa perspectiva é a obtenção de um conhecimento jurídico que, para ser obtido com maior grau de segurança exige o cumprimento dos passos corretos, ordenados, tarefa esta imposta pelo método científico.

Vale destacar, desde o início, que a metodologia da pesquisa jurídica não se confunde com a lógica jurídica, embora ambos sejam ramos do conhecimento, a preocupação daquela é com os meios para se obter resultados cientificamente válidos, a partir de diversos tipos de métodos científicos possíveis de serem seguidos, a 
depender da natureza da ciência que se está produzindo. A escolha do método correto é essencial para a obtenção dos resultados esperados. Enquanto a lógica jurídica é o estudo do pensamento e de sua organização, bem como das formas pelas quais se chega aos resultados de argumentação.

Portanto, o estudo da lógica jurídica, em outras palavras, a construção da linguagem jurídica, é diferente dos estudos dos critérios utilizados para se produzir ciência jurídica, que aqui será desenvolvido. (BITTAR, 2015, p. 32). Na ciência jurídica, os problemas de pesquisa, não necessariamente obedecem a uma ordem lógica ou uma só fonte, podem derivar da lei, mas podem derivar de um fato que evoque questões epistemológicas, axiológicas, ou mesmo da doutrina ou ainda da vida prática. As evidências podem ser confirmadas, igualmente, a partir de fontes diferenciadas e não apenas as fontes bibliográficas.

Apesar disso, não se pode dissociar completamente esses dois ramos, uma vez que o jurista expõe a sua pesquisa e as suas descobertas também por meio de textos jurídicos e, para tanto, precisa de um discurso jurídico apto a obter e comunicar o conhecimento, transferi-lo e, mais, a convencer o leitor de que suas ideias fazem sentido. Já o discurso científico, no sentido de resultado da pesquisa jurídica, surge após a construção de um conjunto metodológico (regras, procedimentos, técnicas e fontes) e, é parte desse conjunto metodológico o objeto que será aqui abordado: as fontes de pesquisa jurídica (BITTAR, 2015, p. 46).

Conforme preciso desenvolver na área jurídica um conhecimento científico que seja disponibilizado para a comunidade acadêmica por meio de periódicos, superando-se assim a cultura exclusiva do livro, principalmente a dos livros dogmáticos como são a maioria doas compêndios e manuais.

\section{A PESQUISA JURÍDICA, A CIÊNCIA E A ARGUMENTAÇÃO}

Para a formação de uma pesquisa sólida e completa, para a elaboração de um discurso jurídico persuasivo e lógico, o pesquisador precisa, antes de tudo, ter disponível uma base de pesquisa que the dê segurança e que the ofereça subsídios suficientes para o melhor desenvolvimento de sua proposta, não só isso, a maneira de utilização dessas técnicas determinará, ao final, se o resultado trará uma solução original para o problema proposto ou a mera reprodução de algo que já está posto. Além disso, a forma de realização será essencial para despertar no leitor o interesse pela pesquisa. Esse particular não está condicionado a utilização de um discurso jurídico lógico, apoiado em silogismos.

Desse modo, a pesquisa científica pode ser classificada a partir de diversos aspectos, mas a classificação que interessa nesse ponto leva em consideração as fontes utilizadas para formar as bases do conhecimento a ser

\footnotetext{
${ }^{5}$ Informação fornecida por Nitish Monebhurrun, no XIII Congresso Brasileiro de Direito Internacional - comércio, globalização e formação do capital social, realizado na Universidade de Fortaleza - UNIFOR, em Fortaleza, em agosto de 2015.
} 
construído, ou melhor, os procedimentos técnicos de elaboração da pesquisa. Nesse sentido, de acordo com Prodanov e Freitas (2013, p. 54), a pesquisa pode ser dividida em dois grandes grupos: as que se apoiam em fontes de papel e as que se apoiam em dados fornecidos por pessoas.

Para a esfera da ciência jurídica, a pesquisas em fontes de papel são as mais usuais, deixando-se de lado as pesquisas baseadas em informações fornecidas por pessoas, além disso, a forma de utilização das fontes de papel tem sido cada vez mais limitada a um tipo específico, o que vem dando ensejo a muitas críticas, vez que os pesquisadores jurídicos têm sido acusados de estarem limitados a apenas reproduzir conhecimento, compilar dados, repetir o que já está dito, sem construir sobre tais informações um senso crítico, uma argumentação jurídica, que desperte para algo novo. (MONEBHURRUN; VARELA, 2013, p. 433)

O algo novo não necessariamente vai surgir de uma metodologia exclusivamente jurídica, mas da aplicação do método científico e de seus critérios para analisar e dar respostas a dado fenômeno. Estes procedimentos não são divergentes, mas complementares, contudo, não se pode afirmar que basta usar uma argumentação jurídica lógica para surgir algo inovador. Esta qualidade é mais provável que surja da rotina da pesquisa científica, seja teórica seja empírica.

Eduardo Bittar (2015, p. 126) afirma que o pesquisador jurídico tem um vício na pesquisa bibliográfica e, quando resolve inovar, em raras oportunidades, utiliza-se da pesquisa documental, porém, sem conseguir se desvencilhar das fontes de papel. Alerta o autor que a utilização equivocada da técnica contamina os resultados que se quer alcançar, mesmo que o pesquisador tenha se dedicado ao máximo, assim, para evitar tal problema, a melhor saída é a conjugação de métodos, a combinação de fontes de pesquisa.

Diante disso, faz-se necessário traçar uma breve explanação sobre alguns tipos de pesquisa, levando em consideração as formas de obtenção de dados, que podem ser aplicadas na ciência jurídica, a fim de se demonstrar a possibilidade de utilização de múltiplos métodos, que permitam ampliar a análise da situação-problema e, dessa forma, ampliar os horizontes do pesquisador para novos rumos da pesquisa jurídica, com consequente produção de conhecimento, ou seja, para que o pesquisador de fato seja capaz de fazer ciência.

A pesquisa bibliográfica é aquela realizada através de fontes secundárias, ou seja, fontes que já receberam um tratamento científico e que se tornaram públicas por meio de textos impressos, cujo conteúdo é resultado de interpretação já realizada acerca do objeto pesquisado. Dessa forma, a pesquisa bibliográfica é essencial para que o pesquisador, após a definição do tema de pesquisa, possa ampliar seus conhecimentos e, inclusive, verificar se o que ele pretende descobrir já não foi descoberto por outra pessoa. (ALMEIDA JÚNIOR, 1988, p. 127)

Vale ressaltar que a pesquisa bibliográfica deve estar presente em todo processo investigativo que necessite de um referencial teórico, porém, atenta-se para que o resultado dela não se corrobore em mera repetição de tudo que fora dito pelos autores estudados de forma resumida, para tanto, o pesquisador precisa 
colocar seu olhar crítico sobre a leitura dos textos, promovendo um diálogo crescente e instigador, que influencie a continuidade da pesquisa por ele próprio ou, ao menos, pelo leitor. (LAKATOS; MARCONI, 2003, p. 183; PRODANOV; FREITAS, 2013, p. 54)

A pesquisa documental também tem por base o papel, porém, trata-se de fonte primária, sobre as quais não foi realizado tratamento analítico, são, portanto, documentos oficiais e originais, que podem ser obtidos em arquivos públicos e arquivos privados, como por exemplo, fotografias, objetos culturais, decisões jurídicas e leis, tudo a depender do objeto de estudo, com a vantagem de se tratar de uma fonte autêntica, livre de influências externas, exceto as pré-compreensões inerentes a todos os sujeitos intérpretes, fruto de sua experiência de vida. (LAKATOS; MARCONI, 2003, p. 174; PÁDUA, 1988, p. 157)

Além dessas fontes clássicas de papel, há outras em que a informação é captada diretamente das pessoas. A entrevista, por exemplo, é técnica por meio da qual se obtêm dados acerca de um determinado assunto através de uma conversa profissional documentada cientificamente em formulário, que deve ser bem estruturado para que se chegue a uma conclusão efetiva sobre o assunto pesquisado. Por intermédio desse tipo de pesquisa, o pesquisador tem contato com quem vivencia aquele problema por ele investigado na prática. (LAKATOS; MARCONI, 2003, p. 195)

De outro modo, caso o pesquisador prefira não ter contato com o objeto de pesquisa, seja para preservar o anonimato do informante, ou para evitar influências, no caso de envolvimento próximo com o problema, para conservar a impessoalidade do instrumento, pode-se utilizar do questionário, que será preenchido na ausência do pesquisador. Destarte, deve já ter em mente uma reflexão avançada sobre o tema de pesquisa, a fim de que possa construir as perguntas de forma direcionadas a aquisição dos resultados. (LAKATOS; MARCONI, 2003, p. 202; PÁDUA, 1988, p. 158)

O estudo de caso é outra técnica que pode ser explorada pelo pesquisador, sobretudo, para contextualizar amplamente o objeto de pesquisa. Para tanto, é necessário extremo comprometimento e organização por parte do pesquisador, com intuito de evitar ao máximo o comprometimento dos resultados obtidos. Por meio do estudo de caso, o pesquisador faz um estudo profundo e exaustivo do objeto para obter um conhecimento detalhado que possa, em síntese, oferecer soluções práticas para problemas sociais. (GOMES; POZZEBON, 1988, p. 147; PRODANOV; FREITAS, 2013, p. 60)

Por fim, tem-se a pesquisa de campo, em que o pesquisador vai até o objeto de estudo para observar como os fatos e os fenômenos ocorrem espontaneamente, com o objetivo de registrá-los para compará-los as hipóteses obtidas previamente por meio de uma pesquisa bibliográfica. Nota-se, portanto, que para realização da pesquisa de campo, o pesquisador já deve ter passado por etapas anteriores de pesquisa bibliográfica e documental, e vai a campo para comprovar o que já fora estudado ou descobrir novos fenômenos ainda não 
documentados. (LAKATOS; MARCONI, 2003, p. 186; PRODANOV; FREITAS, 2013, p. 59)

O estudo de caso e a pesquisa de campo em muito se parecem, de fato, pode-se dizer que o estudo de caso consiste numa espécie do gênero pesquisa de campo, cujo objeto é de grande complexidade e envolve fatores múltiplos de investigação, que devem ser interralacionados para ao final se obter resultados de aplicação prática ao contexto social. Destaca-se que podem ser considerados casos de pesquisa um indivíduo, um grupo de pessoas, uma comunidade, uma organização regional ou nacional. (ARAÚJO et. al., 2008, p. 4)

Existem, ainda, alguns outros métodos ou técnicas de pesquisa que podem ser utilizados na elaboração de trabalhos científicos das mais diversas áreas de estudo, mas, tendo em vista os objetivos do presente artigo, os métodos até então explanados são suficientes para evidenciar a possibilidade de compatibilização dos mesmos com a pesquisa no âmbito do jurídico, a fim de fugir das amarras da tendência bibliográfica para demonstrar a compatibilidade na utilização dos métodos de forma conjunta como meio de enriquecer o trabalho do pesquisador.

Vladmir Silveira e Samyra Haydêe Sanches (2016, p. 170): “É preciso desenvolver na área jurídica um conhecimento científico que seja disponibilizado para a comunidade acadêmica por meio de periódicos, superando-se assim a cultura exclusiva do livro, principalmente a dos livros dogmáticos como são a maioria doas compêndios e manuais".

\section{A COMPATIBILIZAÇÃO ENTRE FONTES DE PESQUiSA E FONTES DO DIREITO PARA PRODUÇÃO DE TRABALHOS CIENTÍFICOS}

As fontes de pesquisa apresentadas devem ser conectadas às próprias fontes do Direito, a fim de melhorar a qualidade jurídica científica dos trabalhos produzidos nessa seara, de modo que ao pesquisador cabe saber adequar o uso das fontes ao objeto jurídico de pesquisa, sem esquecer que o Direito é, também, uma ciência social, portanto, de fins práticos, cujos problemas merecem soluções viáveis de serem aplicadas na vida real, daí porque não se permite mais discussões meramente teóricas, em que os resultados fogem da práxis.

O Direito é uma ciência que nasce da reunião dos homens em sociedade, com finalidade de regular as relações humanas e as condições de existência dos indivíduos para obtenção de um convívio harmônico e pacífico na sociedade através do estabelecimento de normas de conduta social. Portanto, a fonte material ou substancial do Direito, ou seja, a sua origem são os fatos que, ao atingirem os seres humanos, de qualquer forma, ganham projeção jurídica e, as fontes formais do direito, os modos pelos quais ele se manifesta na sociedade, são as normas, costumes e a jurisprudência. (RÁO, 2013, p. 64-65; VENOSA, 2007, p.9)

O Direito brasileiro estabeleceu expressamente algumas de suas fontes no art. $4^{\circ}$, do Decreto-Lei ${ }^{\circ}$ 
4.657, de 4 de setembro de 1942, a Lei de Introdução às Normas do Direito Brasileiro - LINDB, que prevê que nos casos em que a lei for omissa, o juiz deverá decidir de acordo com a analogia, os costumes e os princípios gerais do direito. Portanto, infere-se de tal previsão que a lei seria a fonte primária e, nos casos não abarcados por ela, caberia a consulta aos costumes e aos princípios gerais do direito, como fontes secundárias.

Além dessas fontes com previsão expressa na legislação, pode-se ainda reconhecer a jurisprudência, sobretudo, após a Constituição de 1988, que trouxe em seu bojo uma série de direitos fundamentais, muitos formados por conceitos abertos, que devem ter seus significados preenchidos através da atividade interpretativa dos juízes. Ressalta-se, também, a existência de súmulas vinculantes ${ }^{6}$, que devem ser observadas por todos os demais Tribunais e pela Administração Pública e, por fim, a adoção da teoria de precedentes pelo novo Código de Processo Civil. ${ }^{7}$

Deste modo, verifica-se que o Direito se manifesta por documentos: leis e decisões jurídicas; por experiências sociais: costumes; e através de valores institucionalizados que recebem tratamento doutrinário, jurisprudencial e, algumas vezes, legal: princípios gerais do direito. Assim, o pesquisador que quer produzir um trabalho científico jurídico deve, ao menos prioritariamente, consultar essas fontes, para só então, e a partir delas, buscar interpretações derivadas sobre o tema, quais sejam, as teorias desenvolvidas por doutrinadores. $(\text { Informação verbal) })^{8}$

A defesa desse roteiro de consulta às fontes não quer dizer, de forma alguma, que a pesquisa bibliográfica não seja importante, pelo contrário, o estudo da doutrina é essencial no processo de descoberta do objeto investigado e da ampliação do conhecimento do pesquisador acerca do tema e de tudo que lhe for correlato. A pesquisa bibliográfica, nesse sentido, é necessária em qualquer trabalho de pesquisa, como etapa do processo de investigação, desde que ao final, o pesquisador tenha o cuidado de formar seu próprio entendimento, por meio de uma argumentação que deixe claro seu senso crítico construído em cima dos textos examinados. (ALMEIDA JÚNIOR, 1988, p. 111; LAKATOS; MARCONI, 2003)

Vale destacar que o problema não está na pesquisa bibliográfica propriamente, mas na maneira como ela tem sido utilizada na área do Direito, limitada normalmente a analise de doutrina brasileira, com raras consultas em livros estrangeiros ou em artigos que, quando utilizados, são retirados de sites, cuja qualidade é questionável,

\footnotetext{
${ }^{6}$ As súmulas vinculantes têm previsão expressa no art. 103-A da Constituição Federal de 1988.

${ }^{7}$ Não constitui objeto do presente artigo dissertar acerca das fontes do Direito especificamente, mas apenas explaná-las com o intui de relacioná-las às fontes de pesquisa. Porém, para maiores esclarecimentos, destaca-se que o novo Código de processo civil, lei no 13.105, de 16 de março de 2015, adotou a teoria dos precedentes a partir do art. 926, que assim dispõe: "Os tribunais devem uniformizar sua jurisprudência e mantê-la estável, íntegra e coerente.” Tal exigência de estabilidade é justamente para dar segurança aos indivíduos em relação à atividade jurisdicional na aplicação de suas próprias decisões anteriores a casos futuros.

${ }^{8}$ Raciocínio elaborado a partir de palestra ministrado por Nitish Monebhurrun, no XIII Congresso Brasileiro de Direito Internacional - comércio, globalização e formação do capital social, realizado na Universidade de Fortaleza - UNIFOR, em Fortaleza, em agosto de 2015.
} 
como por exemplo, jus navigandi, segundo periódico mais citado em teses de doutorado, "revista" em que o processo de seleção para publicação é de pouco rigor, motivos pelos quais a pesquisa bibliográfica tem sido objeto de frequentes críticas no âmbito jurídico. (MONEBHURRUN; VARELA, 2013, p. 432)

A pesquisa de campo e o estudo de caso também são compatíveis com o Direito, uma vez que este, conforme já explanado, é produto da realidade social. Ir a campo para observar como tem sido aplicada determinada norma, ou qual a reação social acerca de uma decisão específica, oferece ao pesquisador outra visão sobre o tema, permitindo-lhe apresentar soluções mais palpáveis e pragmáticas a sua situação problema, além de tornar a leitura do trabalho jurídico bem mais interessante e enriquecedora, tanto dentro do universo dos juristas, quanto para aqueles profissionais de outros ramos.

A utilização da jurisprudência para análise de casos práticos também é uma forma de compatibilizar fontes de pesquisa empíricas com fontes do Direito, pois engloba um estudo completo sobre o tema ao envolver a análise do documento legal, que será aplicada ao caso concreto; dos acontecimentos sedimentados culturalmente, os costumes; e da bibliografia, interpretação teórica dos institutos jurídicos; além de constituir instrumento de pesquisa apto à produção de trabalhos jurídicos científicos originais e inovadores, pois os casos avaliados juridicamente nunca são totalmente iguais, contêm suas particularidades.

Assim sendo, um bom trabalho jurídico científico precisa ter como fontes de pesquisa, primordialmente, as próprias fontes do Direito, o que permite a utilização de técnicas para além da bibliográfica, como, conforme mencionado, a pesquisa documental, a pesquisa de campo e o estudo de caso. Fontes estas que enriquecerão a pesquisa, vez que são aptas a promover a aquisição de conhecimento amplo ao pesquisador, que desenvolverá melhor o seu senso crítico acerca do tema estudado e, assim, poderá produzir resultados mais condizentes com a realidade, com uma contribuição real para ciência do Direito.

\section{CONSIDERAÇÕES FINAIS}

Destarte, conforme exposto, para que a pesquisa possa ser considerada científica, é imprescindível a observação de um método que proporcione organização e ordem ao processo de investigação, a fim de que, ao final, possa-se apresentar uma contribuição científica. Nesse sentido, é o método (e fontes) que dá cientificidade a todo e qualquer processo de busca de soluções para as situações problemas levantadas pelos pesquisadores, de qualquer ramo do conhecimento. Dentro desse método existem técnicas para obtenção de dados e de informações necessárias a formação do pensamento crítico do pesquisador acerca do tema.

Somente o pesquisador que se mostre capaz de construir seu próprio raciocínio, ou sua própria argumentação lógica, em relação ao objeto pesquisado, através da demonstração do método utilizado e da 
comprovação dos resultados apresentados, pode afirmar que conhece o tema e que, a partir desse conhecimento, é apto a produzir ciência, no sentido de inovar, de acrescentar algo novo à comunidade científica e, sobretudo, à sociedade.

No Direito, especificamente, os trabalhos jurídicos, como exaustivamente afirmado em linhas anteriores, não têm obtido sucesso nesse sentido, pois, das inúmeras monografias de conclusão de curso, dissertações de mestrado, teses de doutorados e artigos enviados para publicação, poucas tem contribuído de fato para a ciência do Direito, principalmente por se limitarem a mera análise de teorias doutrinárias já conhecidas por todos os juristas da área acadêmica e profissional.

Exatamente por isso, faz-se imprescindível a reavaliação da forma de se fazer pesquisa no Direito, a começar pelas fontes que têm sido utilizadas pelos pesquisadores jurídicos, que, apesar de trabalharem diariamente com fatos sociais, concretos, reais, na hora de pesquisar, optam por basear-se eminentemente em fontes bibliográficas, quando muito, em fontes documentais, e pior, normalmente, em livros monográficos nacionais, sem sequer se permitirem um estudo de Direito comparado ou de artigos científicos recentemente publicados, que tendem a trazer uma abordagem mais atual sobre o tema estudado.

Restou debatido que esta restrição não é, de forma alguma, um problema da ciência jurídica, mas sim do pesquisador, que não explora as fontes de manifestação de seu próprio ramo de conhecimento, o Direito, o que Thes abriria possibilidades para utilização de outras técnicas de coleta de dados e de resolução de problemas, como por exemplo, pesquisa de campo e estudo de caso, inclusive, a partir de decisões de Tribunais, que é a fonte que mais se aproxima da realidade, uma vez que direcionada aos casos concretos.

Para deixar mais claro pode-se inclusive exemplificar: uma pesquisa que se proponha verificar se a decisão de um Tribunal acerca de determinada garantia tem, de fato, aplicabilidade prática, pode, além de estudar o plano teórico das garantias e das competências dos juízes para decidir sobre elas, ir a campo, entrevistar pessoas diretamente afetadas por aquela decisão, verificar sua efetividade no plano concreto, para ao final demonstrar se realmente o objetivo foi alcançado ou se é preciso repensar a forma de garantir direitos.

Não se pode esquecer que o Direito é uma ciência social, portanto, produzido a partir da sociedade e para a sociedade, por isso as pesquisas jurídicas devem ser capazes de fazer essa interrelação entre o que está positivado, o que é decidido, e o que de fato ocorre na realidade. Abrir os olhos da população, informando-a do que está acontecendo com seus direitos, também é papel do pesquisador jurista, mais que isso, ele deve, ainda, apresentar soluções práaticas para esses problemas, o que só é possível através de um estudo completo sobre o tema, que se utilize das melhores técnicas que tiver disponível.

Assim, a adequada utilização das fontes de pesquisa, especialmente, compatibilizadas às fontes do Direito, pode sim influenciar diretamente na melhoria de qualidade dos trabalhos jurídicos científicos e, 
consequentemente, na produção do conhecimento jurídico científico, pois a pesquisa que combina técnicas de estudos bibliográficos com técnicas de estudos empíricos torna-se mais rica e abre ao pesquisador um universo novo, do qual ele pode coletar peculiaridades e particularidades que ainda não foram coletadas por outras pessoas, ou se foram, o foram de forma diversa e, a partir daí produzir algo novo, com aplicação prática.

\title{
THE ADEQUACY OF THE LEgaL RESEARCH SOURCES FOR THE PRODUCTION OF INNOVATIVE LEGAL AND SCIENTIFIC KNOWLEDGE
}

\begin{abstract}
The focus of this article is to treat about the adequacy of the legal research sources for the production of scientific legal expertise as well as its compatibility with their own sources of law. The problem raise from the contemporary criticism about the legal work, especially with regard to limiting the use of bibliographic research, based primarily on monographic books, being important to discuss sources of legal research to alert the researcher that there are different ways and possibilities for research in law. Thus, we seek to answer how the way to use the legal research sources can directly influence the quality of the legal work and consequently the production of scientific legal knowledge. Therefor, this article has as main objective to evaluate the appropriate use of sources (as well, the use of appropriate sources) legal research is responsible for producing an original and innovative scientific legal knowledge. The specific objectives, in turn, consists in presenting the various options for legal research sources in the field of law and demonstrate the need for communication and compatibility between the types of source of legal scientific research and the sources of law. In the methodological aspect, this article is developed through a literature search, based on classical scientific methodology books and journal articles, and a documentary search, since it uses sources which have not undergone any scientific tract, for example, information captured from the seminar conducted during the XIII Brazilian Congress of International Law, held at the University of Fortaleza. The search is also on the approach, the qualitative kind, as part of the reflection on the human and social actions. As for the objects, it is descriptive and exploratory, as it seeks to describe, explain, clarify and interpret the observed problem. Regarding the use of the results is the pure kind, since it has the intention to expand knowledge on the subject and everything that surrounds it. That said, it appears that it is necessary to the legal and scientific researcher using various types of possible sources of research, not limited exclusively to literature, since in a manner consistent to the research subject and own sources of law, to We can innovate in the production of legal knowledge through scientific legal work of the highest quality, which in fact present practical and workable
\end{abstract}


solutions to the problems.

Keywords: Legal research sources; Legal and scientific knowledge; Law sources.

\section{REFERENCIAS}

ALMEIDA JÚNIOR, João Baptista de. O estudo como forma de pesquisa. In: CARVALHO, Maria Cecília M. de (Org.). Construindo o saber: técnicas de metodologia científica. Campinas: Papirus, 1988. Segunda parte, Cap. 1, p. $107-129$.

ARAÚJO, Cidália et al. Estudo de caso. 2008. Disponível em: <http://grupo4te.com.sapo.pt/estudo_caso.pdf〉. Acesso em: 27 set. 2015.

BITTAR, Eduardo C. B. Metodologia da pesquisa jurídica: teoria e prática da monografia para os cursos de Direito. 13. ed. São Paulo: Saraiva, 2015.

FREITAS, Ernani Cesar de; PRODANOV, Cleber Cristiano. Metodologia do trabalho científico: métodos e técnicas da pesquisa e do trabalho acadêmico. 2. ed. Novo Hamburgo: Feevale, 2013.

GIL„Antonio Carlos. Métodos e técnicas de pesquisa social / Antonio Carlos Gill. - 6. ed. - São Paulo : Atlas, 2008.

GOMES, Paulo de Tarso; POZZEBON, Paulo Moacir Godoy. Técnicas de dinâmica de grupo. In: CARVALHO, Maria Cecília M. de (Org.). Construindo o saber: técnicas de metodologia científica. Campinas: Papirus, 1988. Segunda parte, Cap. 3, p. $141-148$.

LAKATOS, Eva Maria; MARCONI, Marina de Andrade. Fundamentos de metodologia científica. 5. ed. São Paulo: Atlas, 2003.

MATALLO JÚNIOR, Heitor. A problemática do conhecimento. In: CARVALHO, Maria Cecília M. de (Org.). Construindo o saber: técnicas de metodologia científica. Campinas: Papirus, 1988. Primeira parte, Cap. 1, p. 11 - 
29.

MEZZAROBA, Orides; MONTEIRO, Cláudia Servilha. Manual de metodologia da pesquisa no direito. São Paulo: Saraiva, 2004.

MONEBHURRUN, Nitish; VARELLA, Marcelo D. O que é uma boa tese de doutorado em Direito? Uma análise a partir da própria percepção dos programas. Revista Brasileira de Políticas Públicas, Brasília, v. 3, n. 2, p.423-443, dez. 2013.

PÁDUA, Elisabeth Matallo Marchesini de. O trabalho monográfico como iniciação à pesquisa científica. In: CARVALHO, Maria Cecília M. de (Org.). Construindo o saber: técnicas de metodologia científica. Campinas: Papirus, 1988. Segunda parte, Cap. 4, p. 149 - 170.

POPPER, Karl R.. Conjecturas e refutações: pensamento científico. Tradução de: Sérgio Bath. 2. ed. Brasília: Universidade de Brasília, 1982.

RÁO, Vicente. O Direito e a vida dos direitos. 7. ed. São Paulo: Revista dos Tribunais, 2013.

SILVEIRA, Vladmir Oliveira de; SANCHES, Samyra Haydêe dal Farra Naspolini. PERIÓDICOS NA ÁREA DO DIREITO: O DESAFIO DA SUPERAÇÃO DA CULTURA DOS LIVROS. Revista da Faculdade de Direito-RFD-UERJ - Rio de Janeiro, n. 30, dez. 2016, p.157-170.

VENOSA, Sílvio de Salvo. Introdução ao estudo do Direito. 2. ed. São Paulo: Atlas, 2007.

Trabalho enviado em 27 de maio de 2018

Aceito em 17 de setembro de 2018 